\title{
A Comparison of Animal Words in English and Chinese Culture
}

\author{
Ting Shi \\ Tianjin Modern Vocational Technology College, 3 Yaguan Road, Tianjin Haihe Education Park, \\ China 300350
}

397656413@qq.com

Keywords: Animal Word; Western and Chinese Culture; Similarity; Difference

\begin{abstract}
Animal words are an indispensable part in our daily life. Our relationship with animals and observation of them provide us with a means of association when we speak. However, in the different cultures of the West and the East, the same animal words may express totally opposite meanings. In this paper, the author will study and analyze these animal words and compare them between the two different cultures.
\end{abstract}

\section{Introduction}

The boundless universe is made up of everything. Animals have a special relationship with mankind. They are men's friends to keep them company so that men do not feel lonely. Meanwhile, the names of animals have also enlarged the human vocabulary, making the meaning of idioms and our language much richer.

The animal is not only an important part of nature, but also an indispensable part of society. At the same time, we can find idioms and expressions with animals' names everywhere in society. Nowadays, these idioms or words, which include animal words, have not merely been the simple symbol of a kind of animal. In most situations, mankind has elaborated on them, enabling them to express human emotions and ideas. [1] One simple animal word can often express different emotions and thoughts. In respect to the differences of culture, region, habits and customs between the East and the West, same kind of animal word represents different meanings. The cultural differences lead to various interpretations feelings, and understanding of the animals. Some animals are imagined by people; and some are worshipped by Easterners, but Westerners are unable to understand. Some are avoided in the West but not eliminated at all in the East. Some expression of animals' names between the East and the West are basically the same, but some are totally different.

The thesis aims to explain my research on the many symbolical meanings of the animals expressed through words in two diverse cultures. [2] This paper selects some representative animal vocabulary to compare and analyze their usage and meaning in the context of Chinese and English.

\section{Comparing Animal Words in English and Chinese}

Positive Meanings in English but Derogatory Meanings in Chinese.The same animal words may have positive meanings in English, but derogatory meanings in Chinese, such as "dog" and "owl". [3]

The basic meaning of the dog is identical in both English and Chinese. It means a kind of animal with four legs and can help people guard the house. But its implications are very different. 
The dog enjoys a unique position in Westerners' mind, so there are numerous words, idioms and proverbs including "dog", such as "as faithful as a dog" and "Love me, love my dog".

In China, words related to dogs usually imply a negative meaning and have a derogatory sense. For instance, zou gou, lang xin gou fei, hu peng gou you. In the Chinese culture, a dog is often abused and it represents a mean, hateful, and immoral character. Westerners, especially the British and the Americans, like to use dogs to describe people who are trustworthy and sympathetic, such as "help a dog over a still (help people come through the difficulty)", "a lucky dog (a lucky fellow)", "an old dog(veteran)", "love me, love my dog". Obviously, these statements have reflected the Westerners' attitude toward a dog. They regard dogs as lovely companions, their best friends, such as "as faithful as a dog" to describe people's loyalty. A great majority of people who raise dogs usually regard dogs as a member of their family. Certainly, not all phrases with dogs in English have a positive meaning. [4] When somebody says "you are a dog", he is not meaning that you are loyal. This American slang contains a negative meaning of hatred. It also means "you are ugly".

By comparing these two languages, the positive meanings associated with dogs in English are still more frequently used and adapted than in Chinese.

Owls are animals which are most active at night and who are notorious for their shrill-like cry that sometimes making people alarmed. [5] In China, owls are often linked with the meaning of bad luck and misfortune, such as the folk saying "if the owl enters the residence, good things do not come".

However, in English, owl represents the meaning of shrewdness and high intelligence, or it is sometimes used to describe people with a serious look. For example, the phrase as "wise as an owl" means a wise man and "Don't provoke him, he is as grave as an owl," describes a person who keeps a stiff face and looks serious. Also, "night owl" means a person who likes to stay awake most of the night to read, work, go out, etc.

Derogatory Meaning in English but Positive Sense in Chinese. The same animal words with a derogatory sense in English can contain a positive sense in Chinese too. This can be found everywhere, for instance, the "peacock" and the "bat".

Westerners are afraid of bats. They think that bats are detestable, and often associate it with ugliness and evil, therefore all idioms using a bat indicate a derogatory meaning in English, such as "as blind as a bat", which means having difficulty in seeing. And another example is "Be/have bats in the belfry" meaning someone to be mad. However, bat is read as bian fu in Chinese, and there is a word pronounced same with " $f u$ " in Chinese character meaning "luck and good fortune". As a result, bats represent good animals in traditional Chinese culture.

The same kind of animal often produces different association between the East and the West because of the differences in aesthetical understanding. The West emphasizes the supercilious attitude of the peacock and usually uses it to describe people who are excellent, beautiful, and proud such as "as proud as a peacock", "play the peacock". However, the East pays attention to the peacock's beauty, especially when it spreads its feathers. The peacock is the symbol of luck and beauty in the Chinese culture.

Dragon is an animal with a mythical legend in both Chinese and Western cultures. However, the lucky and honorable "dragon" in the East is contrasted with the evil, fierce, and cruel dragon in the West. [6]In the Chinese culture, dragons symbolize luck, authority, nobility, and prosperity. The Chinese nation is called the "successor of the dragon." In past feudal society, a dragon was the emperor's symbol. The past emperors all call themselves "the emperor of a real dragon ". Even nowadays, a dragon is the loftiest animal in the minds of the Chinese people because we call our 
own country "the eastern huge dragon." Dragons can be regarded as the totem of the Chinese nation. Chinese have a lot of idioms related to dragons such as long teng hu yue, long fei feng wu.

But in the western culture, people think that dragons are evil representatives, and a kind of ferocious, strange beast with devil's incarnation. The differences between Chinese and English give the same animal different implications. The images that are brought to two cultural mindsets are divergent. If people want to introduce the term "dragon" to Westerners, it will be less confusing to use the phrase "the Chinese dragon" instead of "the dragon." For example, to avoid any misinterpretation from the West we should translate "the Four little Dragons in Asia" into "Four tigers" in English. [7]

Cow in English means a woman who is pregnant many times or is really fat. Bull refers to a foreman and a guardian. But in Chinese, cow usually represents the public servant, such as "the old ox", meaning the person who is willing to serve the people whole-heartedly.

Similar Meaning Both in Chinese and English. Some parts of the culture between the East and the West are similar. The use of language is also alike. Some animal words represent similar meanings, for instance, "snake", "lion" and "tiger".

In the eyes of both the Chinese and English people, the snake stands for evil and danger. A snake in the grass is particularly dangerous because it is difficult to spot. Do we have a "friend" who is kind to us when we meet face to face but talk bad things behind your back? That person may be called a snake in the grass. [8] His evil words will "bite" you like a snake. For example:

I had always suspected him of being a snake in a grass; and now that he had betrayed his best friend, my suspicions were confirmed.

Also, "Look before you leap, for snakes among the bright flowers creep."This proverb remind -s us that even in the happy times we should think of the consequences before doing things. We can avoid danger if we get into the habit of thinking ahead. [9]

Chinese people regard tigers as the king of all beasts. "There are no tigers in the mountain, the monkey calls the king." is one of the examples. In English, the tiger's throne is substituted by the lion.

Westerners usually use lions instead of tigers to represent the imperial power. In the chronicle of Narnia, series written by C.S.Lewis, the main character is a lion called Aslan who plays the King, the Lord of the whole wood in the story. The lion is also the national emblem of Great Britain.

Both tigers and lions are also implications for dangerous places in both Chinese and English context. They also carry a meaning of boldness and might. "Lion heart" means a warrior; "the lion's share" means the most of the share. [10]

The horse is a kind of animal which has strength and represents high-speed. Since the ancient times, horses have been playing an important role in transportation, sports and on the battle field. In Chinese, a horse implies running fast, such as kuai ma jia bian and yi ma ping chuan. Because horses have been tamed by mankind, some phrases or idioms with the word horse also share the meaning in obeying other people's orders, such as ma shou shi zhan which means follows the lead. In the West, horses also have the meaning of quick. And they sometimes have the meaning of arrogance. "Be on one's high horse" means someone who acts haughtily. For example:

Miss Ingram, who had now seated herself with proud grace at the piano...commenced a brilliant prelude...She appeared to be on her high horse tonight...

Frequently Appears in English but Rarely Uses in Chinese. Animal words like the word "cat" is frequently used in English to express thoughts and feelings, but they are rarely used this 
way in Chinese. In Chinese, there are few expressions or idioms that contain the word "cat". It is commonly used to describe the agile skill of a person.

In English, however, this word frequently appears. The word "cat" is the symbol of the Western culture. Westerners' culture with cats are fully embodied in their language, for example: "a fat cat"means a rich and powerful person; "an old cat" means a bad-tempered old woman; "a copy cat" means to plagiarize other's work or behavior; "a barber's cat" means a person with a morbid look, "a dead cat" means strong criticism, being ridiculed and attacked by other people. In the West, nearly all kinds of cats are welcomed by people, except black cat because of superstitious reasons. A black cat is considered "unlucky."

\section{Animal Words and Culture}

Language and culture are inseparable. They depend on each other for living, and affect each other for further development. One's language faithfully reflects a nation's complete history, culture, entertainment, beliefs and its prejudices. As for the relationship between language and culture, we can draw such a conclusion: Culture includes the language. Conversely, the language is the embodiment of culture. All phenomenon of culture and society can be reflected in one's language. Nearly each aspect of human lives is influenced by one's own culture. We can say that the culture is the basic backdrop of humans' life. Each kind of culture has its unique style and connotations. Language itself expresses one kind of culture, and it is also a special culture. It has the function of preserving and carrying cultural information. As one kind of symbolism, it must accumulate the features of culture along with inevitable and unceasing changes and become the brand mark of a nation.

In language systems, words and phrases are the closest and most sensitive parts of culture. Since ancient times, the human's survival and development are closely bound up with animals. Some animals has been personified or regarded as gods to be worshiped by people. Thanks to the distinctive images and prominent characteristics of them since long time ago. People have used animal words to describe people or things, and entrust them with rich culture connotations. Animal words are a huge part in the language system both in English and Chinese. They can fully manifest the different values, psychological, and social style of the West and the East that we can reflect upon each of its unique cultures.

\section{Conclusion}

Animal words are quite widespread in the Chinese and English language. Language is a part of culture. By the analysis and the comparison of animal words between Chinese and English, we can conclude that: firstly, the Eastern and the Western cultures have similar viewpoints in certain aspects, but in most areas, they are distinctly different; secondly, the expressions used with animal words in English are richer than in Chinese, which also points to the various influences of different societies and cultural backgrounds in its respective languages.

\section{References}

[1] Guangrong Liao: Contrast between English and Chinese Culturally-loaded Animal Words: Journal of Foreign Languages, (2000) No. 129. In Chinese. 
[2] Yanchang Deng, Runqing Liu: Language and Culture (Foreign Language Teaching and Research Press, China 1989, p 83). In Chinese.

[3] Yanhui Qin, Li Yang: Differences in Cultural Connotations of Animal Words in English and Chinese and their Translation : Journal of Jilin Institute of Chemical Technology, Vol. 31(2014) No. 6. In Chinese.

[4] Jun Zhu: Differences and Translation of the Cultural Connotations of Animal Words both in English and Chinese in the Light of Intercultural Communication (MS., Central China Normal University, China, 2003), p. 18.

[5] Eugene A Nida: Language, Culture, and Translation (Shanghai Foreign Language Education Press, China, 1993 ).

[6] Nailu Jin: Explanation of Chinese Culture (Beijng Language and Culture University Press, China, 1999, p. 185). In Chinese.

[7] Jingyu Bai: Culture and Translation (China Social Sciences Press, China, 2010).

[8] Information on http://www.3edu.net/lw/3/lw_10606.html

[9] Kairong Tan: A Comparison of Cultural Connotations between English and Chinese Animal Words: Read and Write Periodical, Vol.5 (2008) No.3. In Chinese.

[10] Youfu Wu: An English-Chinese Dictionary of Animal Words and their Usage (Shanghai Foreign Language Education Press, China, 1998 ). 